\title{
Study of Site Effects in Kobe Area Using Microtremors
}

\author{
Messele Haile, ${ }^{1}$ Kazuoh Seo, ${ }^{1, *}$ Katsumi Kurita, ${ }^{1}$ Hideo Kyuke, ${ }^{1}$ \\ Hiroaki Yamanaka, ${ }^{1}$ Kensuke Yamazaki, ${ }^{2}$ and Akiko Nakamaru ${ }^{1}$ \\ ${ }^{1}$ Tokyo Institute of Technology, Midori-ku, Yokohama 226, Japan \\ ${ }^{2}$ Tokyo Gakugei University, Koganei 184, Japan
}

\begin{abstract}
In this study, an attempt was made to examine the effect of site conditions on damage distribution in the Kobe City area, after the Hyogo-ken Nanbu earthquake of Jan. 17, 1995, using measured microtremors. A preliminary measurement of microtremors was done between Feb. 18 and 21, 1995. Based on the findings of the preliminary measurement, a more detailed investigation was made between March 4 and 6, 1995. In both cases continuous-stationary measurements and mobile measurements were made. The measured microtremors in the Kobe area showed site-dependent variation in time history, spectral amplitude, spectral ratio, and predominant period. Stiff soil sites showed lower values of amplitude both in time history and spectral amplitude, while soft and deep soil formations showed higher values. The predominant periods also varied in relation to the soil formation in some of the cases. The damage distribution of building structures, especially that of low-rise structures including wooden houses, showed good relation with the characteristics of measured microtremors.
\end{abstract}

\section{Introduction}

The study of site effects during strong ground motion can be made by various methods. The use of measured microtremors for the study of site effects is based on the principle that microtremors propagate in the ground and are amplified at periods which are synchronous with the predominant period of the site due to features of selective resonance. After the pioneering works of Kanai and Tanaka (Kanai et al., 1954; Kanai and Tanaka, 1961; Tanaka et al., 1968) a lot of effort has been made to apply microtremors for site effect studies (Katz, 1976; Katz and Bellon, 1978; Ohta et al., 1978; Kagami et al., 1982, 1986; Kobayashi et al., 1986a, b; Seo et al., 1991; Seo and Samano, 1992; Nakamura, 1989). Some of the above works concentrated on shortperiod microtremors while others used long-period microtremors. Most of them interpreted microtremors by making a Fourier analysis and computing spectral ratio taken at different sites by normalizing over a reference point. Nakamura (1989) used the spectral ratio between the horizontal and vertical components to indicate site transfer function by assuming the vertical component at

Received July 27, 1995; Accepted September 17, 1996

* To whom correspondence should be addressed. ground surface as a substitute of the horizontal component at the basement.

In a wide sense, the findings of the above works can be generalized as follows: period distribution and spectral shapes of microtremors follow a definite pattern for a particular site and resemble the strong ground motion at that given site. But this conclusion has the following significant limitations. 1) Microtremors operate at a very low strain level as compared to strong ground motion, which results in higher strain levels inducing non-linearity. 2) The effect of source on microtremors is significant. Shortperiod microtremors less than $1 \mathrm{~s}$ in length are substantially affected by direct sources like traffic noise, while longer-period microtremors are affected by environmental conditions like atmospheric pressure and ocean waves. Removing the effects of these sources is not so direct. 3) Microtremors are more difficult to apply when the subsurface formation is complicated. Irrespective of these short comings, microtremors show site-dependent variations when measured and interpreted carefully. Besides, microtremors have an advantage over other methods used for site effect studies because of simplicity, ease of use, low cost, and the shorter time required for 


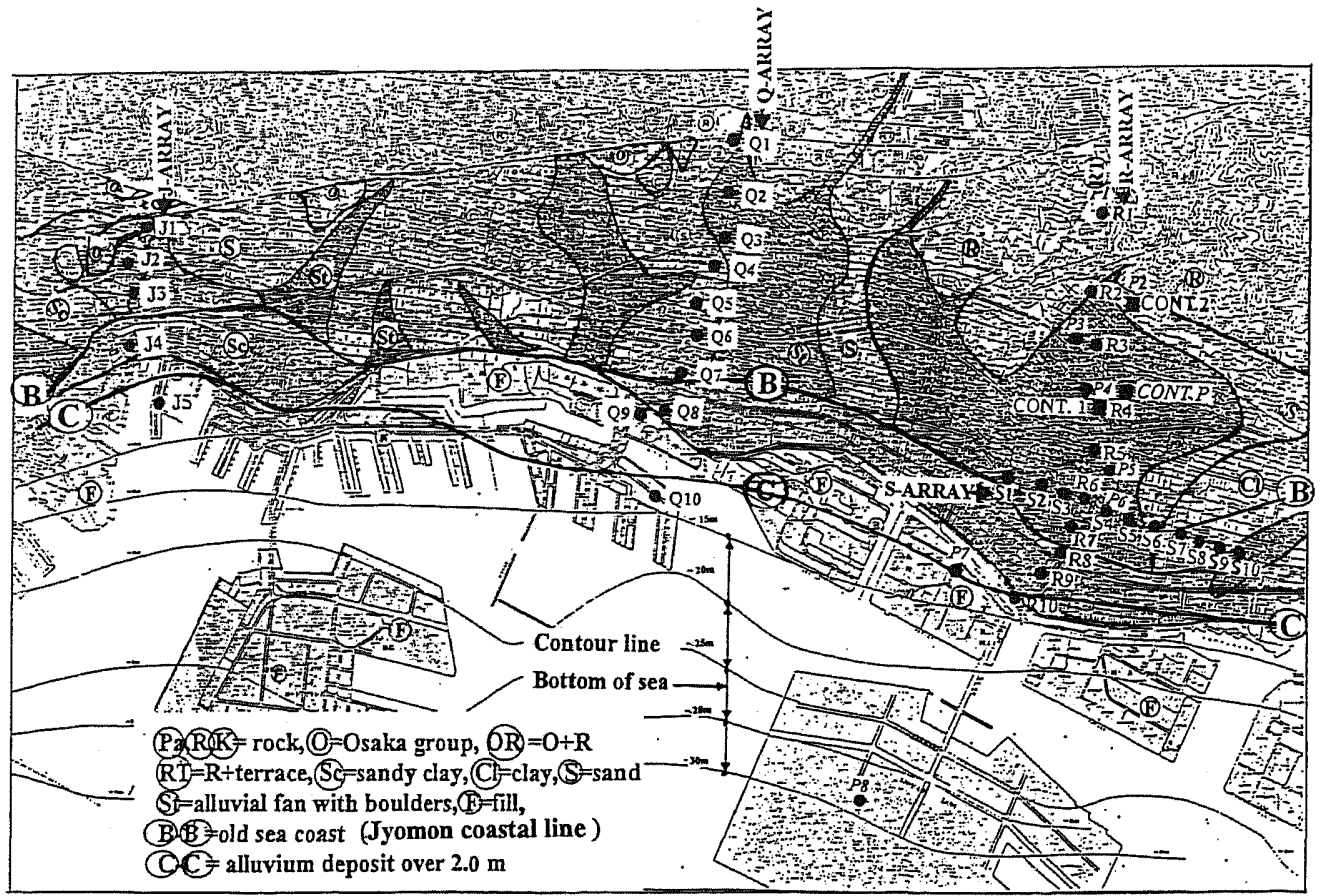

Fig. 1. Locations of microtremor measurement points in Kobe Feb. 18-22 and March 04-06, 1995 (figure adopted from Taisei Corp., 1995).

observation and data analysis. In an attempt to understand the effect of site condition on damage distribution during the Hyogo-ken Nanbu earthquake of Jan. 17, 1995, microtremor measurements were made in Kobe City. A preliminary measurement of short-period microtremors was made between Feb. 18 and 21, 1995. This measurement consisted of stationary continuous measurements made every hour at CONT. P (Fig. 1; hereafter all location references to measurement points (CONT., $\mathbf{P}, \mathrm{J}, \mathrm{Q}, \mathbf{R}, \mathbf{S})$ are as in Fig. 1) and a line array of mobile measurements at eight locations (P1-P8) on different soil formations.

Based on the findings of the preliminary measurements, which indicated that microtremors show site-dependent variation and an acceptable level of stability both in period and amplitude, a more detailed investigation was made between March 4 and 6, 1995. Here both short and long-period microtremors were measured. In this measurement, two sets of continuous measurements were made every hour at two sites. (CONT. 1 and CONT. 2). Besides the continuous measurements, four sets of line arrays of mobile measurements $(\mathrm{J}, \mathrm{Q}, \mathrm{R}$, and $\mathrm{S}$ arrays) were made over a wider area than the preliminary measurement.

\section{Microtremor Measurement and Analysis}

\subsection{Methods of measurement and analysis}

During this measurement, three sets of highly sensitive seismometers, with three orthogonal components each, were used. The seismometers used a moving coil system. The natural period of all the instruments was $1 \mathrm{~s}$, but could be extended to $5 \mathrm{~s}$ electrically. The period response of the seismometers is shown in Fig. 2. The natural periods of the instruments were set to 1 and $5 \mathrm{~s}$ for short-period and long-period microtremor measurements, respectively. The short-period microtremor measurements, with an instrument's natural period set to $1 \mathrm{~s}$, were intended to observe short-period (Kanai's) microtremors with more sensitivity. The measurements made with an instrument's natural period set to $5 \mathrm{~s}$ included both shorter and longer-period microtremors with a decrease in overall sensitivity. They were intended to study formations, including relatively deeper soil formations extending below hundreds of meters. The displacement amplitude of 
microtremors, which is more clear for on-site visual observation, was measured. The obtained signals were amplified depending on the characteristic of each site, and digitized before being recorded on a

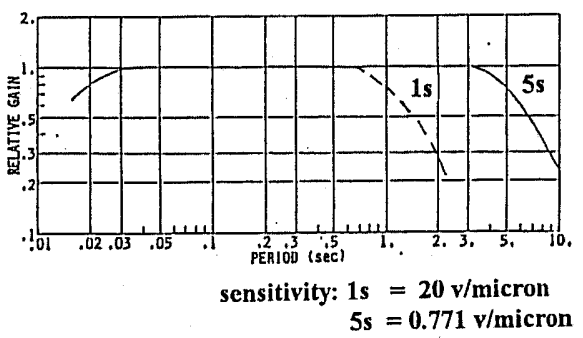

Fig. 2. Overall response curve of microtremor measuring system $(\mathrm{V} / \mu \mathrm{m})$ normalized over the maximum values for both 1 and $5 \mathrm{~s}$.

(a)

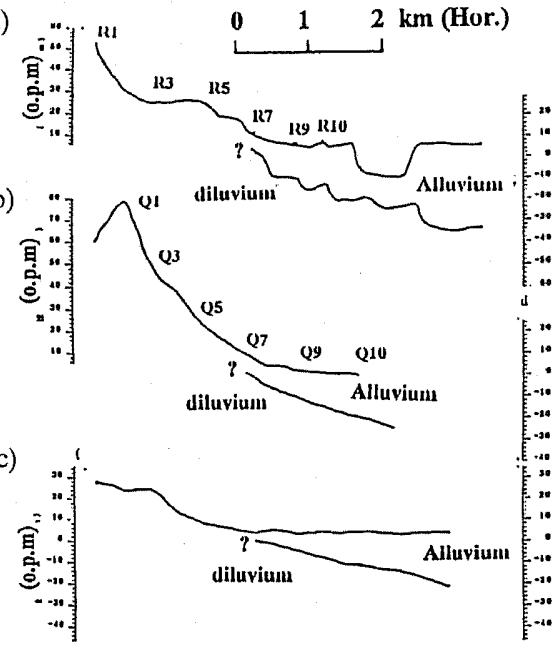

laptop computer. This measurement setup has a merit in that it is possible to make on-site preliminary analysis and display, enabling immediate remeasurement if obtained data has some problem, like contamination with a high-amplitude direct noise generated by passing vehicles or a machine operating very close to the measuring point.

Each data at a point has a displacement time history of $300 \mathrm{~s}$. The velocity response spectra, which gives clearer information for the period ranges of interest in this study ( 0.1 to $5 \mathrm{~s}$ ), were computed. Fourier analysis was made by dividing each record into seven segments and taking the mean values. Segments with big direct noise from close by sources were removed, and the stable part of the time history was used for further analysis. Smoothing was done using a Parzen window of $0.3 \mathrm{~Hz}$ in width. A two-

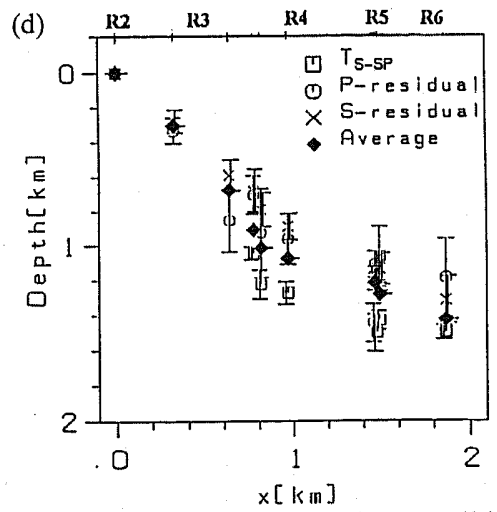

(e)
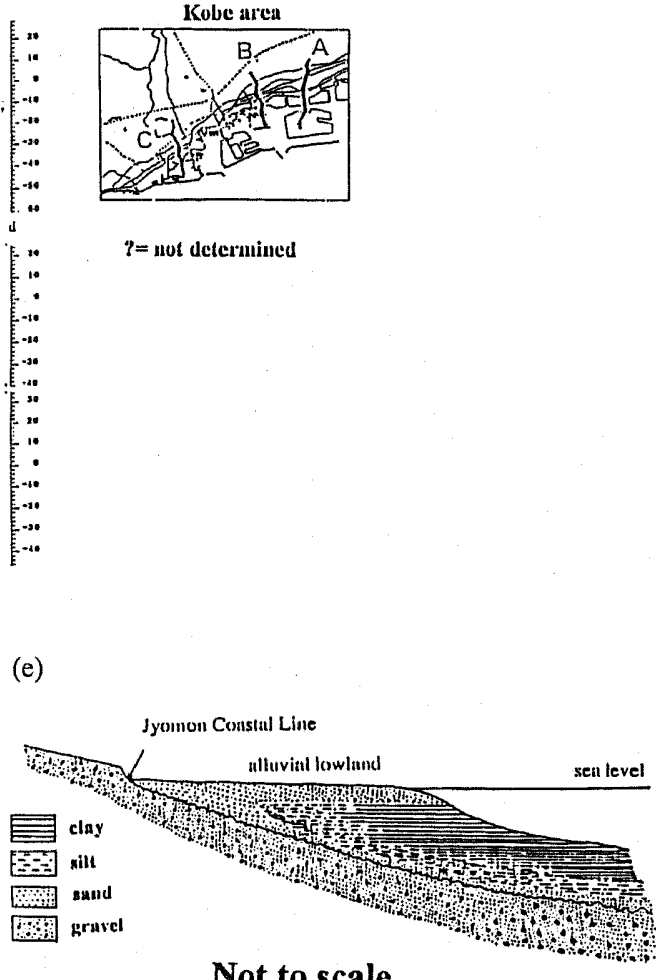

Not to scale

Fig. 3. Ground profiles in Kobe area ((a), (b), (c), and (e) adopted from AIJ, 1995; (d) adopted from Yamanaka and Aoi, 1996). (a) Shallow depth profile along R and P arrays. (b) Shallow depth profile along $Q$ array. (c) Shallow depth profile out of measurement area. (d) Distribution of basement depth estimated from travel time analysis of $\mathrm{P}$ and $\mathrm{S}$-waves. $\mathrm{R}$ and $\mathrm{P}$ arrays. (e) Representative stratum in Kobe area.

Vol. 45, No. 2, 1997 
dimensional horizontal component (H2D) was computed by taking geometric averages with NS and EW components. For the mobile measurement, spectral ratios were computed by normalizing over the most stable point in each particular array. The velocity Fourier amplitude spectra, spectral ratio, and relative variation of amplitude were computed and plotted.

\subsection{Preliminary measurement}

This was a short-period microtremor measurement with the instrument's natural period set to $1 \mathrm{~s}$. It consisted of a continuous stationary measurement, which was taken to check the period and amplitude stability characteristic of microtremors

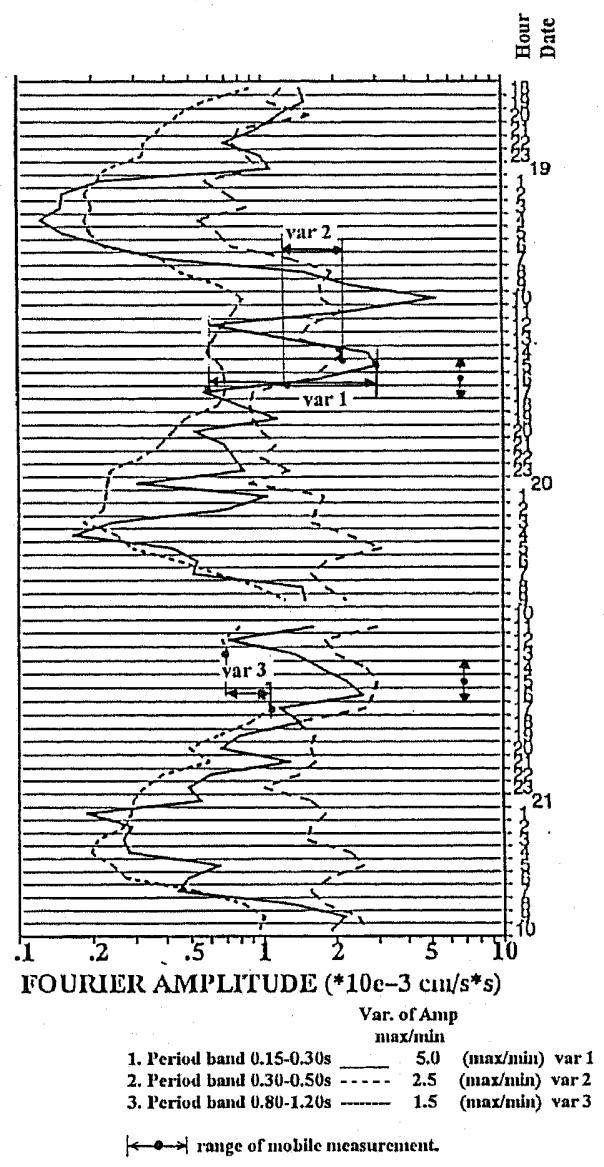

Fig. 4. Hourly variation of microtremors, preliminary measurement (CONT. P). The maximum/ minimum amplitude ratios are calculated for short, medium, and longer-period ranges corresponding to hours of mobile measurements. in the area, and a mobile measurement, which was made to check if microtremors exhibit a site-dependent variation at different points.

\subsubsection{Stationary continuous measurement (CONT. P)}

This continuous measurement was made inside the class room of Kobe Commercial High School, on a thin alluvial fan sediment overlying a diluvial deposit (Figs. 1 and 3) every hour from 18:00 on Feb. 18 to 10:00 on Feb. 21. The purpose of this measurement was to check the period and amplitude stability of microtremors in the area. The amplitudes of the continuous measurement showed as much as 20 times variation in the period range shorter than

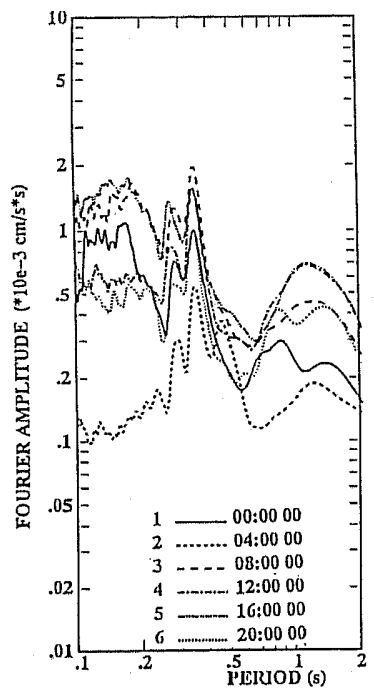

Fig. 5. The velocity Fourier amplitude spectra of hourly variations for preliminary measurement (CONT. P). Every 4-h values are plotted.

Table 1. Date and hours of preliminary measurement.

\begin{tabular}{|c|c|c|c|}
\hline \multirow{2}{*}{ No. } & \multirow{2}{*}{ Array } & \multicolumn{2}{|c|}{ Measurement } \\
\hline & & Date & Hour \\
\hline 1 & $\mathrm{Pl}$ & Feb. 20 & $14: 06: 36$ \\
\hline 2 & P2 & 20 & $14: 33: 13$ \\
\hline 3 & P3 & 20 & $14: 53: 35$ \\
\hline 4 & P4 & 20 & $15: 37: 07$ \\
\hline 5 & P5 & 20 & $16: 21: 00$ \\
\hline 6 & P6 & 19 & $17: 59: 35$ \\
\hline 7 & P7 & 19 & $17: 59: 35$ \\
\hline 8 & P8 & 19 & $16: 32: 43$ \\
\hline
\end{tabular}


$0.2 \mathrm{~s}$ (Figs. 4 and 5). This is because of varying human activity with the minimum value at 04:00 in the morning and maximum values during the daytime, especially at 08:00 and 16:00. This fluctuation reduces to about 4 times in a period of $1 \mathrm{~s}$. The variation of amplitude corresponding to the hours of mobile measurements from 14:00 to 18:00 (Table 1) is about 5 times at periods shorter than $0.2 \mathrm{~s}$, about 2.5 times between $0.3-0.5 \mathrm{~s}$ and about 1.5 times for periods of around $1 \mathrm{~s}$ (Fig. 4). Con- cerning the predominant period, good stability was observed. The predominant period at $0.35 \mathrm{~s}$ (Fig. 5) is expected to be from the 4-story R.C. building in which this measurement was made. The predominant periods around $0.26 \mathrm{~s}$ (Fig. 5) are understood as reflecting the predominant periods of the site. The predominant period around $1 \mathrm{~s}$ showed some variation. As the preliminary measurement was done with the instrument's natural period set to $1 \mathrm{~s}$, it is difficult to discuss longer periods here.
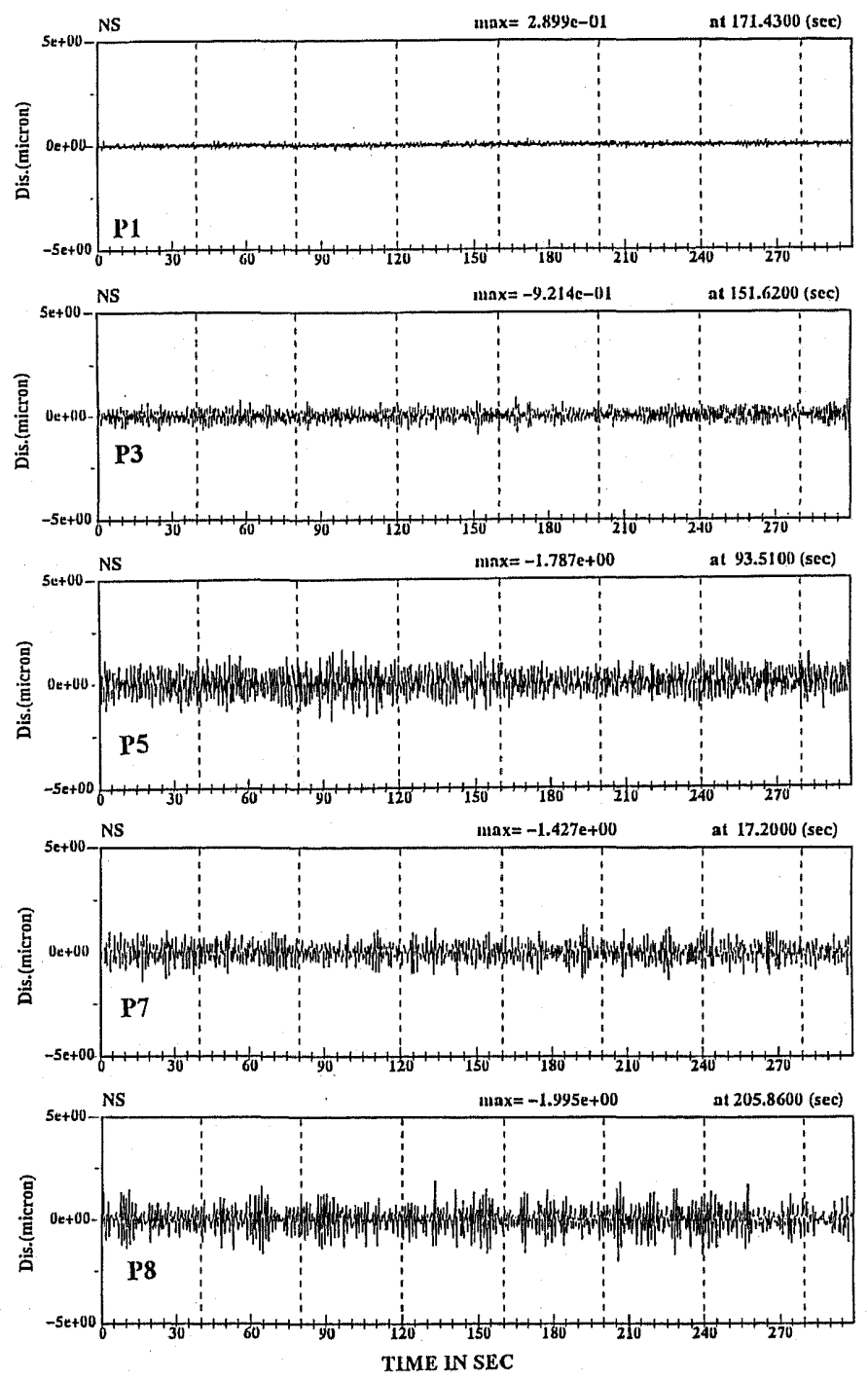

Fig. 6. Displacement time history of microtremors (NS-Comp 1s) preliminary measurement (P) for every other point. 


\subsubsection{Mobile measurement (P1-P8)}

A line array measurement of eight points was made starting from a rock site at the foot of the Rokko mountain range, crossing through a thin alluvial fan sediment overlying diluvial and alluvial deposits, reclaimed land area and to Rokko artificial island (Figs. 1 and 3). The amplitude of the displacement time history for every other point (Fig. 6) and the velocity Fourier amplitude spectra (Fig. 7) showed a site-dependent systematic variation. In the spectra, the smallest amplitude was observed at rock site $\mathrm{P} 1$, increasing slightly at $\mathrm{P} 2$, further increasing in the diluvial soil overlain by a thin alluvial fan (P3, P4, and P5) and decreasing slightly at $\mathrm{P} 6$ presumably due to some local stiffeness in the soil. Sites P7 and P8, which are located in the reclaimed soil sites, show small amplitude at shorter periods and big amplitude around $1 \mathrm{~s}$. Even within the same type of deposit (P3, P4, and P5), the amplitude increased as we moved from the north to the south because of the increase in sediment thickness (Fig. 3(a) and (d)). Concerning the predominant period (Fig. 7), all the sites showed a predominant period around $1 \mathrm{~s}$. In the shorterperiod range, the stiffer formations $\mathrm{P} 1$ and $\mathrm{P} 2$ showed a predominant period around 0.2 and $0.3 \mathrm{~s}$ with very small amplitude. P3 showed a clearer predominant period around $0.2 \mathrm{~s}$. The alluvial

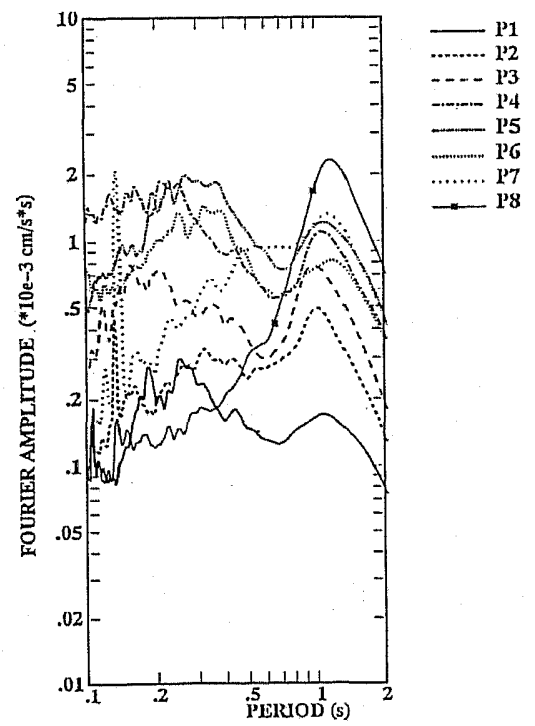

Fig. 7. The velocity Fourier amplitude spectra (H2DComp $1 \mathrm{~s}$ ) preliminary measurement (P) for all points. deposits (P4, P5, and P6) showed periods between 0.2 and $0.4 \mathrm{~s}$, while the artificial fill sites ( $\mathrm{P} 7$ and $\mathrm{P} 8$ ) showed no clear predominant period in shorter periods. This could be due to a thicker clay deposit overlain by more uniform man-made fill without shallow sublayers (Fig. 3(e)).

From the preliminary measurement, no significant instability was observed. The variation of amplitude between the different sites was about 15 times (Fig. 7) on the average in most period ranges. This was much larger than the hourly variation of the continuous measurement, for all period ranges, corresponding to the hours of mobile measurement. Therefore, the variation shown between the different sites in the mobile measurements is understood to be mainly related to the soil condition at each site.

\subsection{Detailed measurement}

The preliminary measurement showed that microtremors show systematic site-dependent variation, both in amplitude and predominant period between different points, consistent with soil formations. Especially, the relative amplification showed good relation with ground formation. The variation in amplitude and predominant period for the stationary continuous measurement showed an acceptable level of stability. Therefore, a more detailed measurement consisting of two continuous measurements and 4 line arrays of mobile measurements was made. For the stationary continuous measurements, long-period microtremors were measured, while both short and long-period microtremors were measured for the mobile measurements. The purpose of the continuous measurements was to confirm if the stability of microtremors observed during the preliminary measurement was consistent at different soil formations in the area. The purpose of the mobile measurements was to cover more area and varied soil formations than in the preliminary measurement. The detailed measurement consisted of the following.

\subsubsection{Two stationary continuous measurements made every hour}

The measurement at CONT. 1 was made from 12:00 on March 4 to 14:00 on March 6 at Konan Elementary and Middle School on a diluvial soil formation overlain by a thin alluvial fan. The measurement at CONT. 2 was made at a Motoyama water filtering plant from 12:00 on March 4 to 09:00 on March 5 on a rock site overlain by slightly 
Table 2. Time of microtremor measurement and damage distribution (detailed measurement).

\begin{tabular}{|c|c|c|c|c|}
\hline \multirow{2}{*}{ No. } & \multirow{2}{*}{ Array } & \multicolumn{2}{|c|}{ Measurement } & \multirow{2}{*}{ Damage* } \\
\hline & & Date & Hour & \\
\hline \multicolumn{5}{|c|}{ March } \\
\hline 1 & $\mathrm{~J} 1$ & 04 & $15: 06: 55$ & ND \\
\hline 2 & $\mathrm{~J} 2$ & 04 & $16: 19: 38$ & LD \\
\hline 3 & $\mathrm{J3}$ & 04 & $16: 45: 45$ & ND \\
\hline 4 & $\mathrm{~J} 4$ & 04 & $17: 20: 14$ & LD \\
\hline 5 & J5 & 04 & $17: 46: 20$ & NS \\
\hline 6 & Q1 & 05 & $11: 49: 11$ & NS \\
\hline 7 & Q2 & 05 & $11: 17: 11$ & NS \\
\hline 8 & Q3 & 05 & $10: 51: 35$ & $\mathrm{LD}$ \\
\hline 9 & Q4 & 05 & $10: 23: 42$ & $\mathrm{MD}$ \\
\hline 10 & Q5 & 05 & $09: 53: 38$ & MD \\
\hline 11 & Q6 & 05 & $09: 24: 02$ & $\mathrm{HD}$ \\
\hline 12 & Q7 & 05 & $20: 41: 37$ & MD \\
\hline 13 & Q8 & 04 & $20: 17: 06$ & LD \\
\hline 14 & Q9 & 04 & $19: 48: 04$ & NS \\
\hline 15 & Q10 & 04 & $19: 20: 24$ & NS \\
\hline 16 & $\mathrm{R} 1$ & 05 & $10: 58: 13$ & NS \\
\hline 17 & $\mathrm{R} 2$ & 05 & $11: 34: 55$ & NS \\
\hline 18 & R3 & 05 & $12: 06: 43$ & LD \\
\hline 19 & $\mathrm{R} 4$ & 05 & $12: 06: 43$ & $\mathrm{LD}$ \\
\hline 20 & R5 & 06 & $09: 44: 32$ & MD \\
\hline 21 & R6 & 06 & $10: 14: 16$ & $\mathrm{HD}$ \\
\hline 22 & R7 & 06 & $10: 37: 03$ & MD \\
\hline 23 & $\mathrm{R} 8$ & 06 & $11: 01: 58$ & MD \\
\hline 24 & R9 & 06 & $11: 37: 28$ & $\mathrm{LD}$ \\
\hline 25 & R10 & 06 & $11: 59: 48$ & NS \\
\hline 26 & Sl & 05 & $14: 20: 33$ & MD \\
\hline 27 & $\mathrm{~S} 2$ & 05 & $14: 41: 12$ & MD \\
\hline 28 & S3 & 05 & $15: 05: 33$ & MD \\
\hline 29 & S4 & 05 & $15: 27: 30$ & HD \\
\hline 30 & S5 & 05 & $15: 51: 02$ & $\mathrm{HD}$ \\
\hline 31 & S6 & 05 & $16: 38: 08$ & HD \\
\hline 32 & S7 & 05 & $16: 34: 15$ & HD \\
\hline 33 & S8 & 05 & $16: 56: 22$ & MD \\
\hline 34 & S9 & 05 & $17: 18: 46$ & MD \\
\hline 35 & $\mathrm{~S} 10$ & 05 & $17: 45: 17$ & $\mathrm{MD}$ \\
\hline
\end{tabular}

* Damage is based on a survey by the Building Research Institute (BRI) for low-rise buildings. $H D$, heavy damage; $\mathrm{MD}$, medium damage; $\mathrm{LD}$, little damage; ND, no damage; NS, no survey.

weathered rock. Within the range of hours corresponding to the mobile measurements (09:00-21:00) (Figs. 8 and 10, Table 2), the stationary continuous measurement at CONT. 1 shows an amplitude variation of up to 4 times in a limited bandwidth

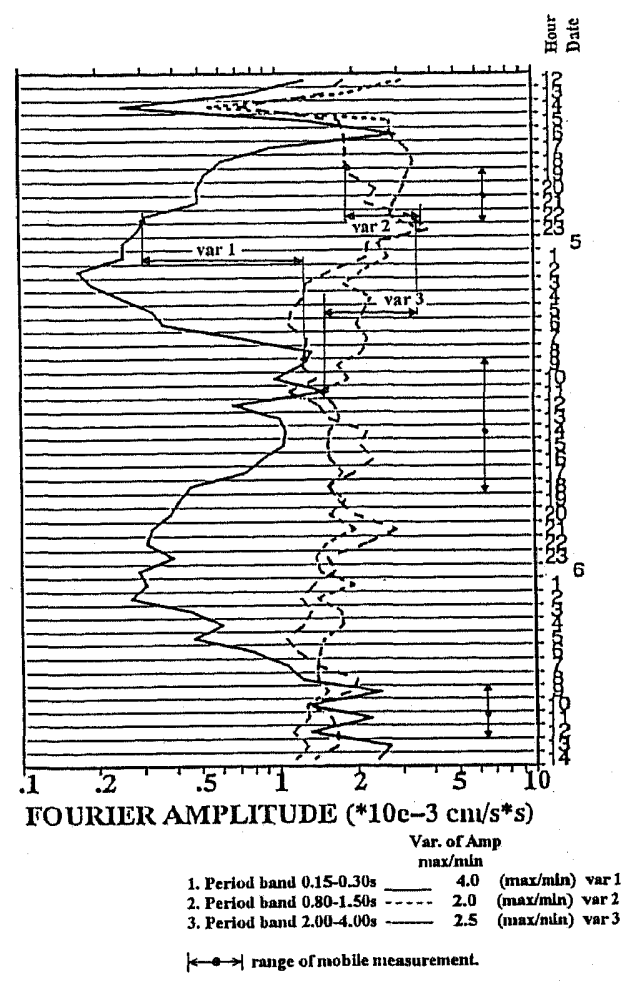

Fig. 8. Hourly variation of microtremors at Konan Elementary and Middle School (CONT. 1). The maximum/minimum amplitude ratios are calculated for short, medium, and longer-period ranges corresponding to hours of mobile measurements.

within the short periods, which was reduced to 2 times at longer periods (Fig. 8). Similarly the stationary continuous measurement at CONT. 2 shows an amplitude variation of less than 3 times at shorter periods, which was reduced to about 1.3 times above $1 \mathrm{~s}$ (Fig. 10). In both cases, the variations in the shorter-period range confirm well with the change in human cultural activity (Figs. 9 and 11), showing a minimum amplitude at 4:00, increasing through the morning and daytime, and falling in the evening.

\subsubsection{Mobile measurements}

The short and long-period microtremor measurements showed similar results to each other for the common period range less than $1 \mathrm{~s}$. Therefore, discussion was made using only the long-period microtremor measurements, without loosing generality. The velocity Fourier amplitude spectra (Figs. 12-15) and spectral ratio normalized over the 


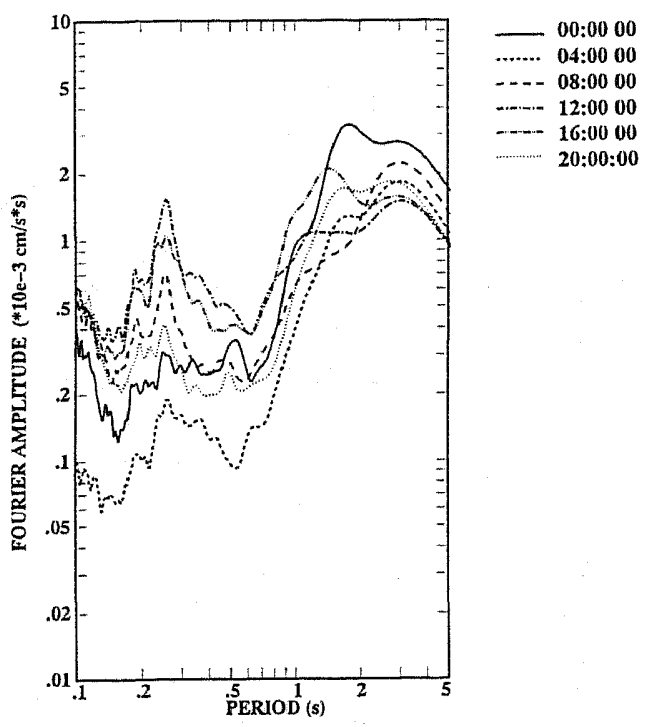

Fig. 9. The velocity Fourier amplitude spectral of hourly variations at Konan Elementary and Middle School (CONT. 1). Every 4-h values are plotted.

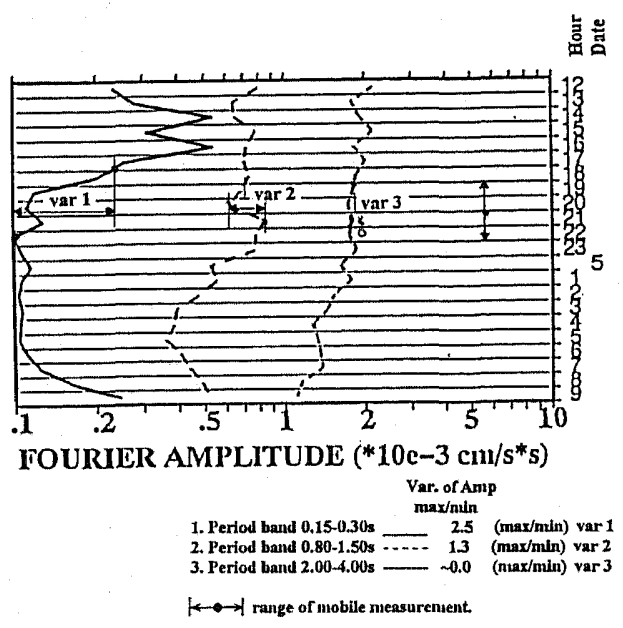

Fig. 10. Hourly variation of microtremors at Motoyama (CONT. 2). The maximum/minimum amplitude ratios are calculated for short, medium, and longer-period ranges corresponding to hours of mobile measurements.

stiffest site in the respective array (Figs. 16-19) are plotted. To make the tracing of curves easier, every other data point is plotted except for the beginning and endpoints of arrays, which are distinct rock and

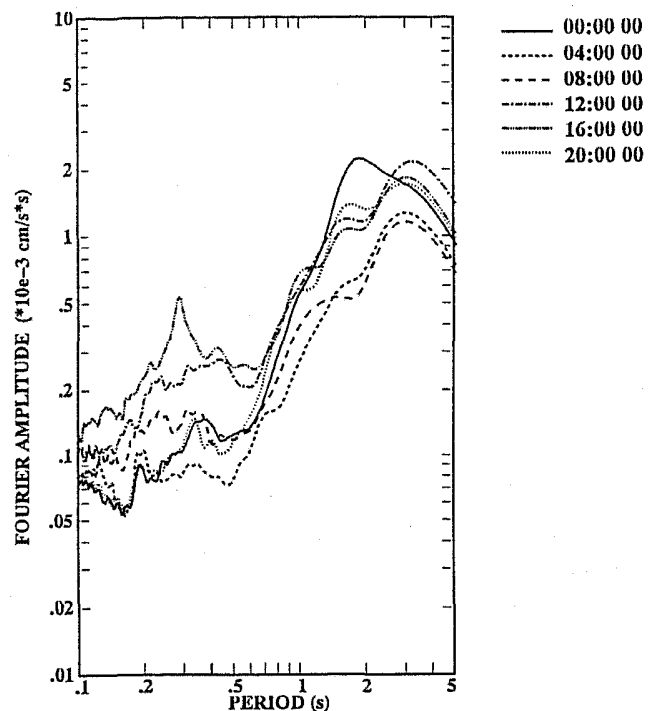

Fig. 11. The velocity Fourier amplitude spectral of hourly variations at Motoyama (CONT. 2). Every 4-h values are plotted.

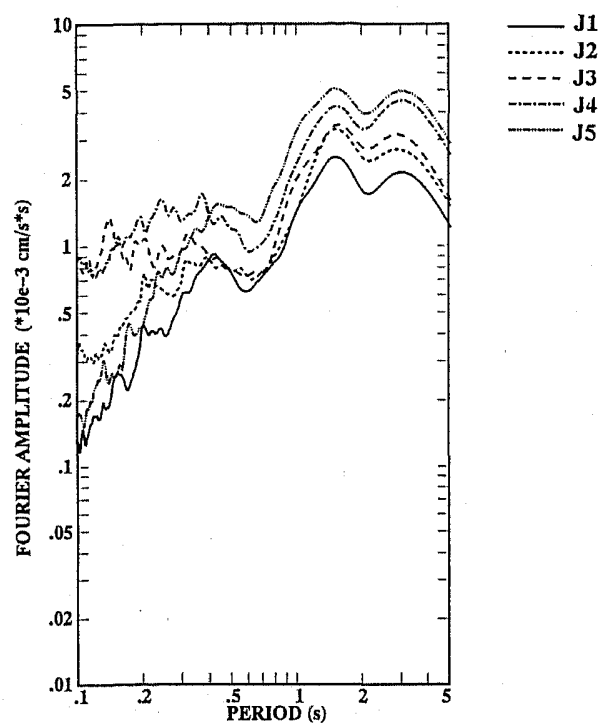

Fig. 12. The velocity Fourier amplitude spectra (H2D-Comp 5s) J-array, for every other point.

artificial fill sites. The mobile measurements consisted of the following.

i) The J-array (J1-J5). This array consisted of 5 points, was measured in Chuo Ward starting at the Japan Meteorological Agency (JMA) in Kobe and 


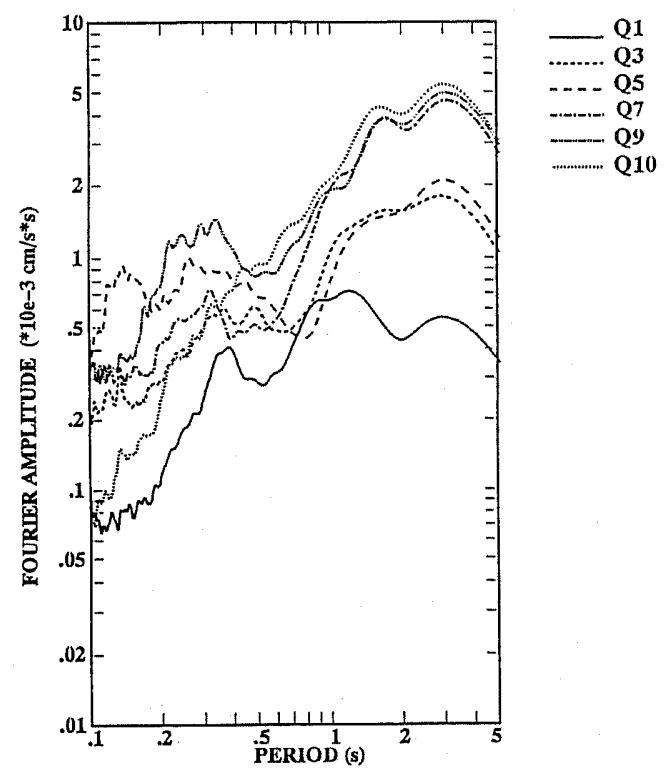

Fig. 13. The velocity Fourier amplitude spectra (H2D-Comp 5s) Q-array, for every other point.

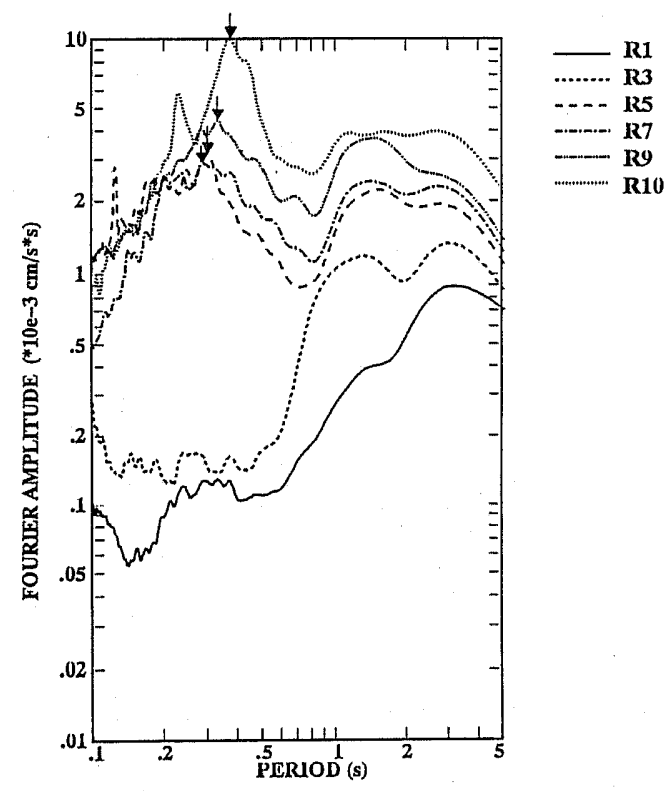

Fig. 14. The velocity Fourier amplitude spectra (H2D-Comp 5s) R-array, for every other point.

ending at Meriken Park. The Fourier amplitude spectra (Fig. 12) shows a systematic increase in amplitude as we moved from the north to south.

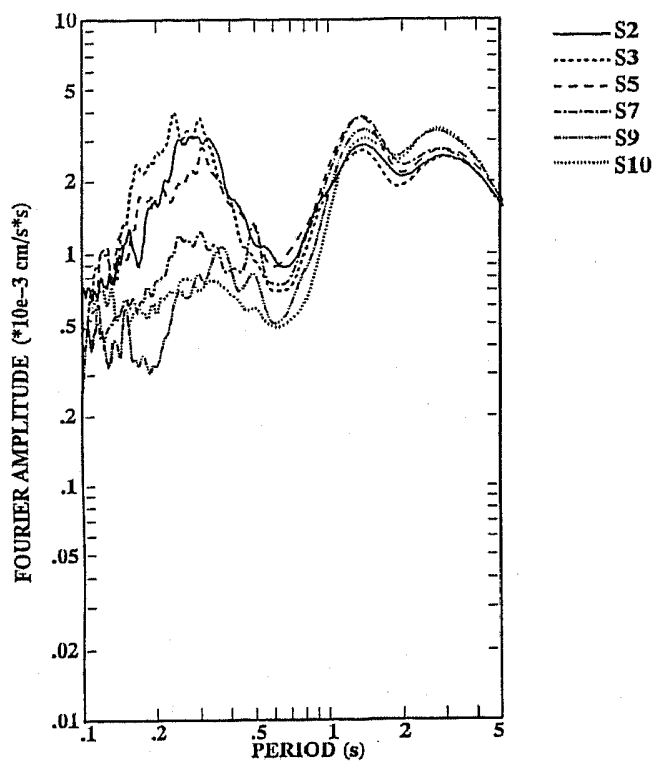

Fig. 15. The velocity Fourier amplitude spectra (H2D-Comp 5s) S-array, for every other point.

The minimum amplitude was observed at $\mathrm{J} 1$, with very shallow deposit over a rock formation, increasing slightly in the diluvial sites ( $\mathrm{J} 2$ and $\mathrm{J} 3$ ) and showing the maximum amplitudes on alluvial deposit (J4) and a reclaimed land site at the harbor (J5). The predominant period for shorter periods appears between 0.2 and $0.5 \mathrm{~s}$. In the longer-period range, a double peak appears at around 1.3 and $3 \mathrm{~s}$. No clear systematic shift in predominant period was observed.

ii) The Q-array $(\mathrm{Q} 1-\mathrm{Q} 10)$. This array was measured in the central part of Nada Ward, consisted of 10 points starting on a rock site at the foot of the Rokko mountain range, passed through diluvial and alluvial deposits and ended at a reclaimed fill soil site. Points Q2 and Q3 are located over a superficial alluvial fan deposit (Figs. 1 and 3). The Fourier amplitude spectra (Fig.13) show a systematic increase in amplitude as we moved from north to south. The minimum amplitude was observed at a rock site (Q1), increasing at the diluvial site (Q3 and Q5), and increasing further at the alluvial deposit (Q7) and reclaimed land sites (Q9 and Q10). The maximum amplification appeared above $0.4-0.5 \mathrm{~s}$ for $\mathrm{Q} 7, \mathrm{Q}$, and $\mathrm{Q} 10$. The predominant periods for the short-period range appeared between 0.25 and $0.5 \mathrm{~s}$. The reclaimed soils

Vol. 45, No. 2, 1997 


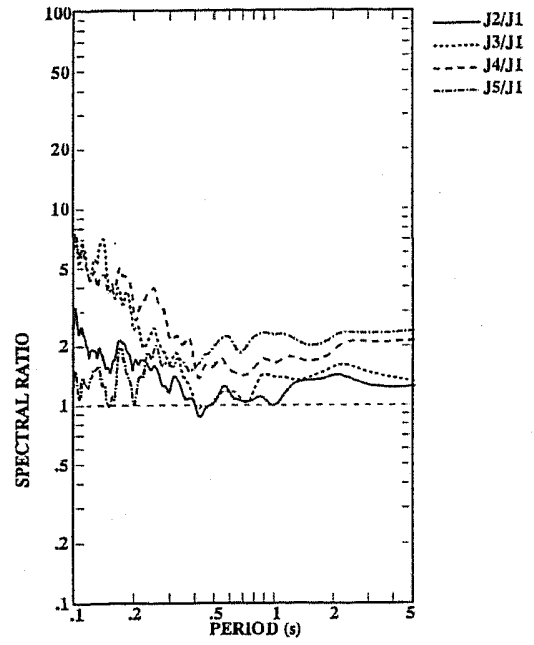

Fig. 16. The velocity Fourier amplitude spectral ratio (H2D-Comp 5s) J-array, for every other point.

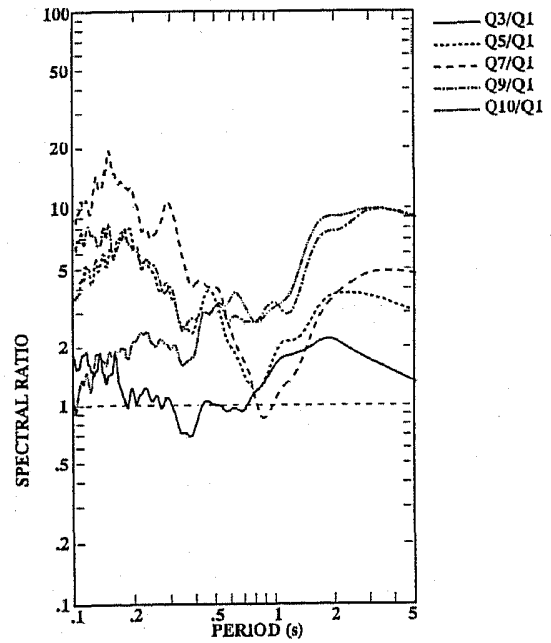

Fig. 17. The velocity Fourier amplitude spectral ratio (H2D-Comp $5 \mathrm{~s}$ ) Q-array, for every other point.

do not show a clear predominant period in the short-period range. In the long-period range, there was indication of a double peak for all sites between 1.3 and $3 \mathrm{~s}$ except for Q3 and Q5, which do not show clear predominant periods around $1.3 \mathrm{~s}$. As in the $\mathrm{J}$-array, here also, the variation in period was not so systematic.

iii) R-array (R1-R10). This array was measured in Higashi Nada Ward, following along the

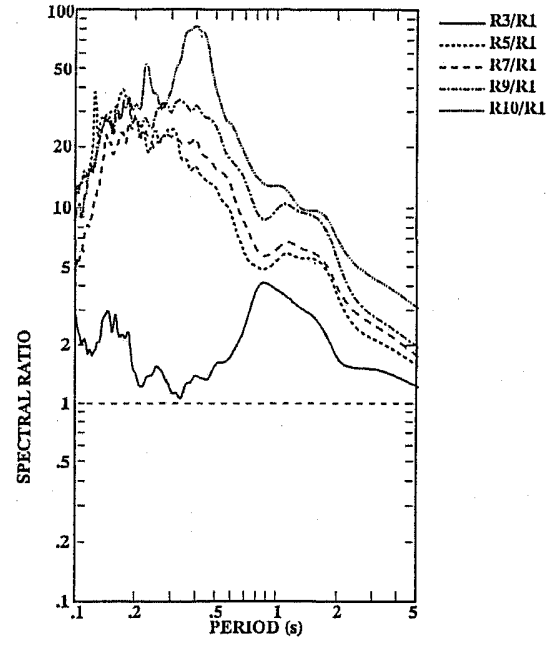

Fig. 18. The velocity Fourier amplitude spectral ratio (H2D-Comp $5 \mathrm{~s}$ ) R-array, for every other point.

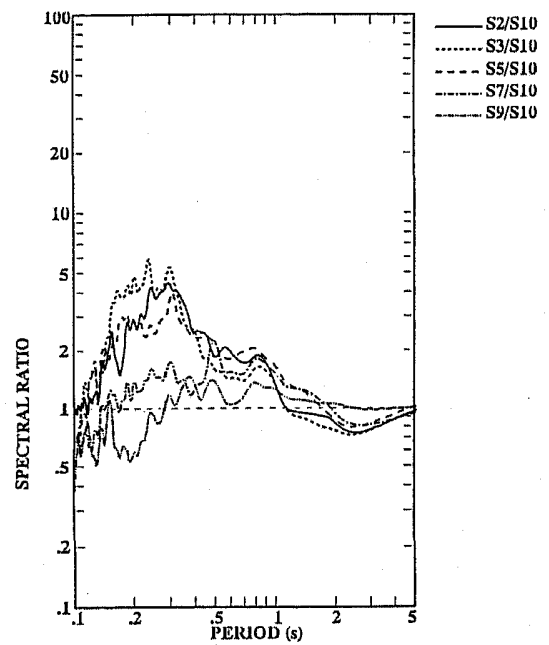

Fig. 19. The velocity Fourier amplitude spectral ratio (H2D-Comp $5 \mathrm{~s}$ ) S-array, for every other point.

Sumiyoshi River. It consisted of 10 points starting from a rock site at the foot of the Rokko mountain range, passed through diluvial, alluvial and reclaimed fill soil sites around the coastal area and ended at Rokko Island. The points between R3 and R7 were on a superficial alluvial fan deposit. In the Fourier amplitude spectra (Fig. 14), the minimum amplitude was observed at a rock site (R1), was slightly higher at diluvial site R3, increased at the 
diluvial deposit R5, and increased further at alluvial deposits R7 and R9. The maximum amplitude was observed on thick alluvium at R10. In the short-period range, the predominant period appears very clearly for sites R5 to R10 with a slight but systematic shift towards longer periods from the north to the south (indicated by arrow in Fig. 14). In the longer period around 1.3 and $3 \mathrm{~s}$, double peaks appeared at all sites except the rock site (R1). The period around $3 \mathrm{~s}$ is not so clear at some of the sites.

iv) S-array (S1-S10). This array runs perpendicular to all the previous arrays. This measurement was made in Higashi Nada Ward across the Sumiyoshi River. All the points are on alluvial deposit although shallow top soil varies from sand to clay. Points S1-S5 and S10 lie on an alluvial fan (Figs. 1 and 3). As shown in Fig. 15, in the short-period range, the minimum amplitude was observed at sites S9 and S10, increasing at S7 and maximum amplitude was observed at sites $\mathrm{S} 2, \mathrm{~S} 3$, and S5. The points furthest from the river showed relatively smaller amplitude. Those points near the Sumiyoshi River showed higher amplitude. In the longer periods above $1 \mathrm{~s}$, the variation in amplitude is small between the different sites, indicating a more uniform soil layer at deeper depth below the alluvial deposit. In the short-period range, the predominant periods appear around $0.3 \mathrm{~s}$. S7 shows another peak around $0.5 \mathrm{~s}$. In the long-period range, clear double peaks appeared around 1.3 and $3 \mathrm{~s}$ for all sites. Data of point S1 was not used due to error during measurement.

The daily variations at short periods were smaller than the variation between the different sites. The variation of amplitude for short periods $(0.2-0.5 \mathrm{~s})$ and long periods above $1 \mathrm{~s}$ are respectively about 4 and 3 times for the J-array (Fig. 12), 4 and 10 for the Q-array (Fig. 13), 80 and 10 for the R-array (Fig. 14), and 5 and 1.5 for the S-array (Fig.15). The variations in the continuous measurements (Figs. 8 and 10) corresponding to the hours of the mobile measurements were smaller than the variations among the different sites. Since there was no significant instability, the stability of microtremors observed during the preliminary measurement was confirmed for other sites of different formations as well as over a wider area. Therefore, the variation between the different sites was understood to reflect mainly the different site conditions.

The computed spectral ratios are shown in Figs.
16-19, for $\mathrm{J}, \mathrm{Q}, \mathrm{R}$, and $\mathrm{S}$ arrays respectively. All the figures show a common pattern. For every observation point in the short-period range, the Fourier amplitude spectra and the corresponding spectral ratio showed no difference in spectral shape; only a relative shift in amplitude was observed due to division by small spectral values for rock sites.

\section{Discussion}

(1) The big variation observed in short periods of less than $1 \mathrm{~s}$ both in amplitude and predominant period could be due to the alluvial fan and delta deposits, shown on the surface geology map in Fig. 1 , which are understood to be very shallow and irregular (AIJ, 1995). They are expected to influence the short-period microtremors corresponding to their respective depths at each site. Generally, microtremors are very sensitive even to small variations. In the longer-period range, predominant periods appear almost at the same period irrespective of site, even if variation in amplitude is observed. As previous studies indicate, variations of predominant period in the longer-period ranges appear more clearly when the contrast between deposit and underlying formation is significant (Kobayashi et al., 1986a, b). When such contrast does not exist, difference could be observed only in amplitude (Kagami et al., 1982, 1986). The results from Kobe resemble the latter case.

(2) The fact that the points in the S-array showed very small variations among each other both in amplitude and predominant period in the longperiod range above $1 \mathrm{~s}$, could be an indication of a uniform structure along the array at deeper formations below the alluvium, while shallow formations varied.

(3) In Kobe, stiff soils are located at the farthest point from the sea, and softer and deeper formations are nearer to the sea. The distance of the furthest array point was about $3 \mathrm{~km}$ from the sea, which is very short compared to the hundreds of kilometers covered by the source for the microseisms. Therefore, even if correction for attenuation is made, the overall trend is not expected to change.

(4) For shorter periods of less than $1 \mathrm{~s}$, the spectral ratio normalized over a rock site showed the same shape as the Fourier amplitude spectra for each observation point. This could be seen by comparing Figs. 12 and 16, Figs. 13 and 17, Figs. 14 and 18, and Figs. 15 and 19 for $J, Q, R$, and $S$ arrays, respectively. This shows that the rock sites

Vol. 45, No. 2, 1997 
provide only a flat spectra. Physically, this could indicate that the short-period microtremors did not have enough energy to excite the rock sites. Therefore, taking spectral ratio, normalization over the rock sites has no meaning for shorter periods and does not remove source effect. In the long period

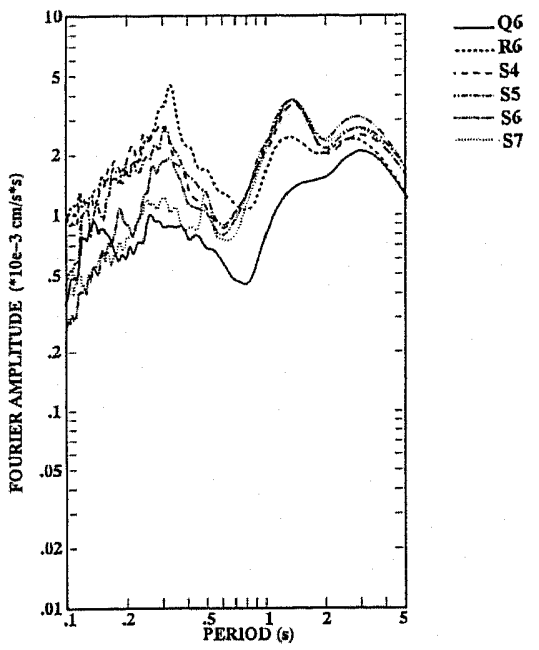

Fig. 20. The velocity Fourier amplitude spectra of points (H2D-Comp $5 \mathrm{~s}$ ) in heavily damaged area. All points are located in heavily damaged area.

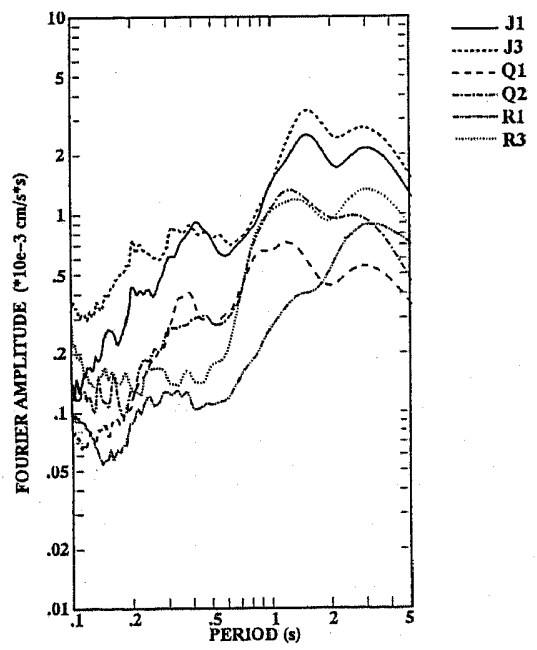

Fig. 21. The velocity Fourier amplitude spectra of points (H2D-Comp $5 \mathrm{~s}$ ) in non-damaged area. Points Q1, Q2, R1, and R3 are classified as no damage based on site survey by the authors. They were not surveyed by BRI (Table 2). above $1 \mathrm{~s}$, differences were observed between the Fourier amplitude spectra and spectral ratio both in amplitude and shape. There was clear amplification over the rock sites, which increased systematically towards softer and deeper formations. This indicated that microseisms exist in both rock and deposit sites, and taking spectral ratio over stiff sites, has physical meaning in removing the source effects.

(5) The observed predominant periods in the short-period range are expected to shift towards longer periods during strong ground motion due to a non-linear effect. It is assumed that they coincide or are close to the natural period of low-rise buildings, which is also shifted due to non-linearity during strong ground motions. Such coincidence of periods contributes significantly to damage.

(6) During our measurements, the observation of tidal waves or atmospheric conditions was not done. Consideration was not given for attenuation due to distance from the sea. The soil profile data for the area, available to the authors, is not precise enough to make a detailed discussion site by site. Consideration of these factors would likely give better results. Irrespective of the above short comings, the measured microtremors showed good agreement with variations in ground formation and damage distribution

\section{Conclusions}

(1) All the arrays running from north to south $(\mathrm{J}, \mathrm{Q}$, and $\mathrm{R}$ ) showed relative amplification from north to south in most period ranges. This amplification is consistent with the soil formation, which starts on a rock site in the north, changes to diluvium, and then to alluvium and artificial fill along the coast. The increase in amplification within the same type of formation is understood as a variation due to the increasing thickness of sediment from the north to the south.

(2) The S-array showed a decrease in amplification in the short-period range as we moved away from the softer and younger shallow-depth deposits around the Sumiyoshi River.

(3) In the short-period range, the site-dependent shift in predominant period is not so systematic and consistent as the variation in amplitude except for the R-array (Fig. 14), which showed a shift in predominant period as we moved from the shallower and stiffer formations in the north to the deeper and softer formations towards the seashore.

(4) The three arrays, J, Q, and R, running 
parallel from the foot of the Rokko mountain range to the sea show marked differences when compared to each other. Considering the maximum value in spectral amplitude for most period ranges, the smallest value was for $\mathrm{J}$-array, increasing with the Q-array, and further increasing with the R-array. As could be seen from Figs. 16 to 18, the maximum variation for short and long periods is about 4 and 3 times for J-array, about 4 and 10 times for Q-array, and about 80 and 10 times for $R$ array, respectively. This confirms to the damage patterns in the respective areas. Around the $\mathrm{J}$-array, the damage was slight and the array is out of intensity 7 anomaly in the area (AIJ, 1995).

(5) Microtremor measurement and damage distribution (Table 2) showed good agreement. Microtremors in the highly damaged area, for low-rise buildings including wooden houses, showed clear amplification around $0.3 \mathrm{~s}$ (Fig. 20). Other sites with no or little damage for such structures showed little amplification at shorter periods (Fig. 21).

(6) A detailed and comprehensive survey with microtremor measurements in the Kobe area could be one of the useful methods for seismic microzonation and disaster mitigation, even when detailed soil profile data is not available.

The authors would like to acknowledge Mr. Masaki Moriuchi, Mr. Kentaro Mori, and Mr. Hiroyuki Sueoka for participating in the measurements, and Prof. Koji Matsunami for helping in the pre-arrangement of measurement sites. Our thanks also to the administrations of Motoyama Filtration Plant, Konan Elementary and Middle School, Kobe Commercial High School, and the Hyogo Prefecture Temporary Shelter at Noyori Park for letting us use their facilities during the measurements. The comments by two reviewers for the Journal of Physics of the Earth are highly appreciated.

\section{REFERENCES}

AIJ, Preliminary Reconnaissance Report of the 1995 Hyogoken-Nambu Earthquake, English ed., Tokyo, 1995.

Kagami, H., C. M. Duke, G. C. Liang, and Y. Ohta, Observation of 1 to 5 second microtremors and their application to earthquake engineering. Part II. Evaluation of site effect upon seismic wave amplification due to extremely deep soil deposits, Bull. Seismol. Soc. Am., 72, 987-998, 1982.

Kagami, H., S. Okada, K. Shiono, M. Oner, M. Dravinski, and A. K. Mal, Observation of 1 to 5 seconds microtremors and their application to earthquake engineering. Part III. A two dimensional study of site effects in the SanFernando valley, Bull. Seismol. Soc. Am., 76, 1801-1812, 1986.

Kanai, K. and T. Tanaka, On microtremors VIII, Bull. Earthq. Res. Inst., Univ. Tokyo, 39, 97-114. 1961.

Kanai, K., T. Tanaka, and K. Osada, Measurement of microtremor I, Bull. Earthq. Res. Inst., Univ. Tokyo, 32, 199-209, 1954.

Katz, L. J., Microtremor analysis of local geological conditions, Bull. Seismol. Soc. Am., 66, 45-60, 1976.

Katz, L. J. and R. S. Bellon, Microtremor site analysis study at Betty, Nevada, Bull. Seismol. Soc. Am., 68, 757-765, 1978.

Kobayashi, H., K. Seo, S. Midorikawa, and S. Kataoka, Measurement of Microtremors in and around Mexico D.F., Part I, Report on Seismic Microzoning Studies of Mexico Earthquake of September 19, 1985, Tokyo Institute of Technology, Yokohama, 1986a.

Kobayashi, H., K. Seo, S. Midorikawa, and S. Kataoka, Estimation of Strong Ground Motion in Mexico City due to the Michioacan Earthquake of September 19, 1985, Based on Characteristic of Microtremors, Part II, Report on Seismic Microzoning Studies of Mexico Earthquake of September 19, 1985, Tokyo Institute of Technology, Yokohama, 1986b.

Nakamura, Y., A method for dynamic characteristic estimation of subsurface using microtremors on ground surface, QR RTRI 30, 1, 25-33, 1989.

Ohta, Y., H. Kagami, N. Goto, and K. Kudo, Observation of 1 to 5 seconds microtremors and their application to earthquake engineering. Part I. Comparison with long period accelerations at the Tokachi-Oki Earthquake of 1968, Bull. Seismol. Soc. Am., 68, 767-779, 1978.

Seo, K. and T. Samano, Prediction of ground motion at Ashigara valley with only microtremor measurements, Proc. Int. Symp. on the Effects of Surface Geology on Seismic Motion, Vol. 2, 125-126, 1992.

Seo, K., T. Samano, H. Yamanaka, X. Hao, S. Koyama, M. Takeuchi, K. Fujioka, Y. Kishino, K. Kawano, K. Asano, N. Nakajima, M. Murai, L. Mualchin, and Y. Hisida, Microtremor Measurements in the San Francisco Bay Area, as a Fundamental Study of Seismic Microzoning, Report, Tokyo Institute of Technology, Yokohama, 1991.

Taisei Corp., Quick Report of the Great Hanshin Earthquake, during the 1995 Hyogoken-Nambu Earthquake, Tokyo, 1995 (in Japanese).

Tanaka, T., K. Kanai, K. Osada, and D. J. Leed, Observation of microtremors XII (case of U.S.A.), Bull. Earthq. Res. Inst., Univ. Tokyo, 46, 1127-1147, 1968.

Yamanaka, H. and S. Aoi, Estimation of basement depth along the Sumiyoshi River in Kobe City-Travel time analysis of P-, S-, and Sp-waves from an earthquake array observation, J. Phys. Earth, 44, 543-552, 1996.

Vol. 45, No. 2, 1997 